\title{
Functional tests to guide management in an adult with loss of function of type-1 angiotensin II receptor
}

\author{
Daan H. H. M. Viering ${ }^{1}$ (D) - Anneke P. Bech ${ }^{2}$. Jeroen H. F. de Baaij ${ }^{1}$ (D) - Eric J. Steenbergen ${ }^{3}$ - A. H. Jan Danser ${ }^{4}$ (D) \\ Jack F. M. Wetzels ${ }^{5}$ (D) René J. M. Bindels ${ }^{1}$ (D) - Jaap Deinum ${ }^{6}$ (D)
}

Received: 18 November 2020 / Revised: 4 February 2021 / Accepted: 17 February 2021 / Published online: 25 March 2021

(C) The Author(s) 2021

\begin{abstract}
Background Genetic loss of function of AGT (angiotensinogen), REN (renin), ACE (angiotensin-converting enzyme), or AGTRI (type-1 angiotensin II receptor) leads to renal tubular dysgenesis (RTD). This syndrome is almost invariably lethal. Most surviving patients reach stage 5 chronic kidney disease at a young age.

Methods Here, we report a 28-year-old male with a homozygous truncating mutation in AGTR1 (p.Arg216*), who survived the perinatal period with a mildly impaired kidney function. In contrast to classic RTD, kidney biopsy showed proximal tubules that were mostly normal. During the subsequent three decades, we observed evidence of both tubular dysfunction (hyperkalemia, metabolic acidosis, salt-wasting and a urinary concentrating defect) and glomerular dysfunction (reduced glomerular filtration rate, currently $\sim 30 \mathrm{~mL} / \mathrm{min} / 1.73 \mathrm{~m}^{2}$, accompanied by proteinuria). To investigate the recurrent and severe hyperkalemia, we performed a patient-tailored functional test and showed that high doses of fludrocortisone induced renal potassium excretion by $155 \%$. Furthermore, fludrocortisone lowered renal sodium excretion by $39 \%$, which would have a mitigating effect on saltwasting. In addition, urinary $\mathrm{pH}$ decreased in response to fludrocortisone. Opposite effects on urinary potassium and $\mathrm{pH}$ occurred with administration of amiloride, further supporting the notion that a collecting duct is present and able to react to fludrocortisone. Conclusions This report provides living proof that even truncating loss-of-function mutations in AGTRI are compatible with life and relatively good GFR and provides evidence for the prescription of fludrocortisone to treat hyperkalemia and salt-wasting in such patients.
\end{abstract}

Keywords Renin-angiotensin system $\cdot$ Renal tubular dysgenesis $\cdot$ Angiotensin II receptor type $1 \cdot$ AGTR1 $\cdot$ Cortical collecting duct

Jaap Deinum

jaap.deinum@radboudumc.nl

1 Department of Physiology, Radboud University Medical Centre, Radboud Institute for Molecular Life Sciences, Nijmegen, the Netherlands

2 Department of Nephrology, Rijnstate, Arnhem, the Netherlands

3 Department of Pathology, Radboud University Medical Centre, Nijmegen, the Netherlands

4 Department of Internal Medicine, Erasmus Medical Centre, Rotterdam, the Netherlands

5 Department of Nephrology, Radboud University Medical Centre, Nijmegen, the Netherlands

6 Department of Internal Medicine, Radboud University Medical Centre, Huispost 463, Geert Grooteplein 8, 6525, GA Nijmegen, the Netherlands

\section{Introduction}

Inhibitors of the renin-angiotensin system (RAS) play an important role in the management of increased cardiovascular and renal risk in the aging population. During fetal development, the RAS regulates kidney perfusion and affects kidney development $[1,2]$. Children with genetic loss-of-function variants in any of the RAS components develop renal tubular dysgenesis (RTD). This clinical syndrome is characterized by poor development of especially proximal tubules, early onset and persistent anuria (often manifesting prenatally) and ossification defects of the skull. Children with pathogenic variants in a RAS component typically die in utero or in the first days of life and develop stage 5 chronic kidney disease (CKD 5) at a young age [3, 4]. Salt-wasting and hyperkalemia have been reported in several cases [5-7]. Biallelic pathogenic variants have been described in four essential genes of the RAS: 
angiotensinogen $(A G T)$, renin (REN), angiotensin-converting enzyme $(A C E)$ and the angiotensin II receptor $(A G T R 1)[3,4]$. Similarly, the use of RAS inhibitors during the second or third trimester of pregnancy can also result in RTD, further stressing the importance of the RAS for normal kidney development $[8,9]$.

Survival without the need for kidney replacement therapy has been described in patients with biallelic pathogenic variants in ACE, AGT or REN [4-7, 10-14]. Nevertheless, several questions remain unanswered. Are full loss-of-function variants in AGTR1, the gene encoding the most important receptor for angiotensin II, compatible with kidney survival? And how should hyperkalemia, salt-wasting and hypotension be treated in a patient with loss of AGTR1 function? Here, we describe the case of a 28-year-old patient with homozygous pathogenic variants in AGTR1 that provides new insights on these questions.

\section{Case description}

The proband, the third son of consanguinous parents of Turkish decent (pedigree in Fig. 1a), came to our attention at the age of 18 years. The pregnancy had been complicated by oligohydramnios, and he was born at $34^{+1}$ weeks' gestation by cesarean section that was urged by decreased variability in fetal heart rate. Apgar scores were 6, 8 and 9 after 1, 5 and $10 \mathrm{~min}$, respectively, and birthweight was $2290 \mathrm{~g}$. He was slightly hypotonic; had large ears, wide fontanelles and hypotelorism; and required oxygen therapy for a short period of time. Ten days post-partum, he developed feeding difficulties and oliguria and was noted to have hypotension (46/25 $\mathrm{mmHg}$ ), severe kidney failure (serum creatinine $335 \mu \mathrm{mol} / \mathrm{L}$ ), hyponatremia (118 mmol/L), hyperkalemia (up to $7 \mathrm{mmol} / \mathrm{L}$ ), metabolic acidosis (7.29), a low transtubular potassium gradient of 3.9 and a mild transient glucosuria $(6 \mathrm{mmol} / \mathrm{L})$ with mild transient aminoaciduria. He was diagnosed with a saltlosing tubulopathy and responded well to intravenous sodium $\left(\mathrm{Na}^{+}\right)$suppleting therapy and potassium $\left(\mathrm{K}^{+}\right)$-binding resins although his blood pressure remained low. In his first year, he depended on gastric tube feeding with $\mathrm{Na}^{+}$suppletion and underwent repair of an inguinal and umbilical hernia. Postoperatively, he developed convulsions with signs of occipital infarction, probably due to severe hypotension. Kidney ultrasounds in the first months of life showed reduced corticomedullary differentiation, and a kidney biopsy at the age of 3 months revealed microcystic dilation of tubules with interstitial changes (Fig. 1). No further investigations were done. In his first year, at least three episodes of acute kidney injury with serum creatinine levels $>250 \mu \mathrm{mol} / \mathrm{L}$ were documented, including the episode shortly after birth.

Pubertal development was normal, but growth lagged behind. He received growth hormone treatment from 11 to 15 years of age and reached an adult height of $178 \mathrm{~cm}$. Cognitive development initially lagged behind that of his peers, but eventually, he completed vocational education. His treating pediatrician noticed that at the age of 10 years, he had unusually elevated plasma renin levels $(12,000 \mathrm{mU} / \mathrm{L}$, normal $<75$ $\mathrm{mU} / \mathrm{L}$ ) and inappropriately low plasma aldosterone levels $(0.03 \mathrm{nmol} / \mathrm{L}$, normal $>0.16 \mathrm{nmol} / \mathrm{L})$. Pathogenic variants in aldosterone synthase (CYP11B2) were ruled out by Sanger sequencing, as were other forms of adrenogenital syndrome. The response of adrenal steroids to cosyntropin stimulation was normal. No further investigations were performed. He was polyuric, which was accompanied by enuresis nocturna until the age of 13. A desmopressin challenge showed that urinary concentrating ability was impaired (maximal urine osmolality $241 \mathrm{mosmol} / \mathrm{L}$ ). He continued his sodium chloride supplementation, and fludrocortisone was added at large dosages (up to $0.3 \mathrm{mg} /$ day) but with little effect on urinary salt loss. At the age of 18, when his estimated GFR (eGFR) was $\sim 45 \mathrm{~mL} / \mathrm{min} / 1.73 \mathrm{~m}^{2}$, he started to develop proteinuria $(0.18$ $\mathrm{g} / \mathrm{L})$. Further medical history was uneventful, except for the chronic presence of cutis verticis gyrata. Also, during childhood, the patient suffered from transient recurrent anemia (4.6-5.7 $\mathrm{mmol} / \mathrm{L}$, treated with erythropoietin).

Currently, at the age of 28 years, his blood pressure is still low (systolic blood pressure around $90-100 \mathrm{mmHg}$ ) with an asymptomatic orthostatic increase of heart rate with $20-30$ beats per minute. Creatinine levels are stable around $200 \mu \mathrm{mol} / \mathrm{L}$ (estimated glomerular filtration rate, eGFR $\sim 30 \mathrm{~mL} / \mathrm{min} / 1.73 \mathrm{~m}^{2}$ ), inversely related to his salt intake. Proteinuria is persistent (protein-creatinine ratio of around $100 \mathrm{mg} / \mathrm{mmol}$ ) and mainly consists of albumin (96\% in last measurement). Despite sodium chloride suppletion and fludrocortisone therapy, his plasma renin levels remain elevated (between 400 and $2000 \mathrm{mU} / \mathrm{L}$ ). The only other medication that he currently receives is 1-hydroxycholecalciferol.

\section{Methods}

\section{Measurement of RAS components}

Blood samples were taken in the seated position after $5 \mathrm{~min}$ of rest. Plasma renin concentration was measured by a standard enzyme-kinetic assay using sheep renin substrate [15], and plasma renin acitivity was measured according to previously described protocols [16]. Plasma angiotensinogen was measured by angiotensin I content [17]. Angiotensin peptides were measured after semipurification, HPLC-separation and radioimmunoassay [16]. At the moment of measurements, the patient was taking $\mathrm{NaCl}$ supplements of up to $9 \mathrm{~g}$ /day and fludrocortisone of $0.3 \mathrm{mg} /$ day. 
a

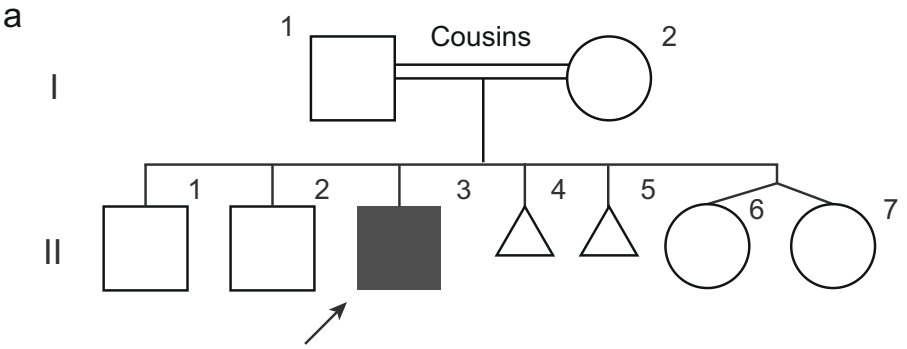

b

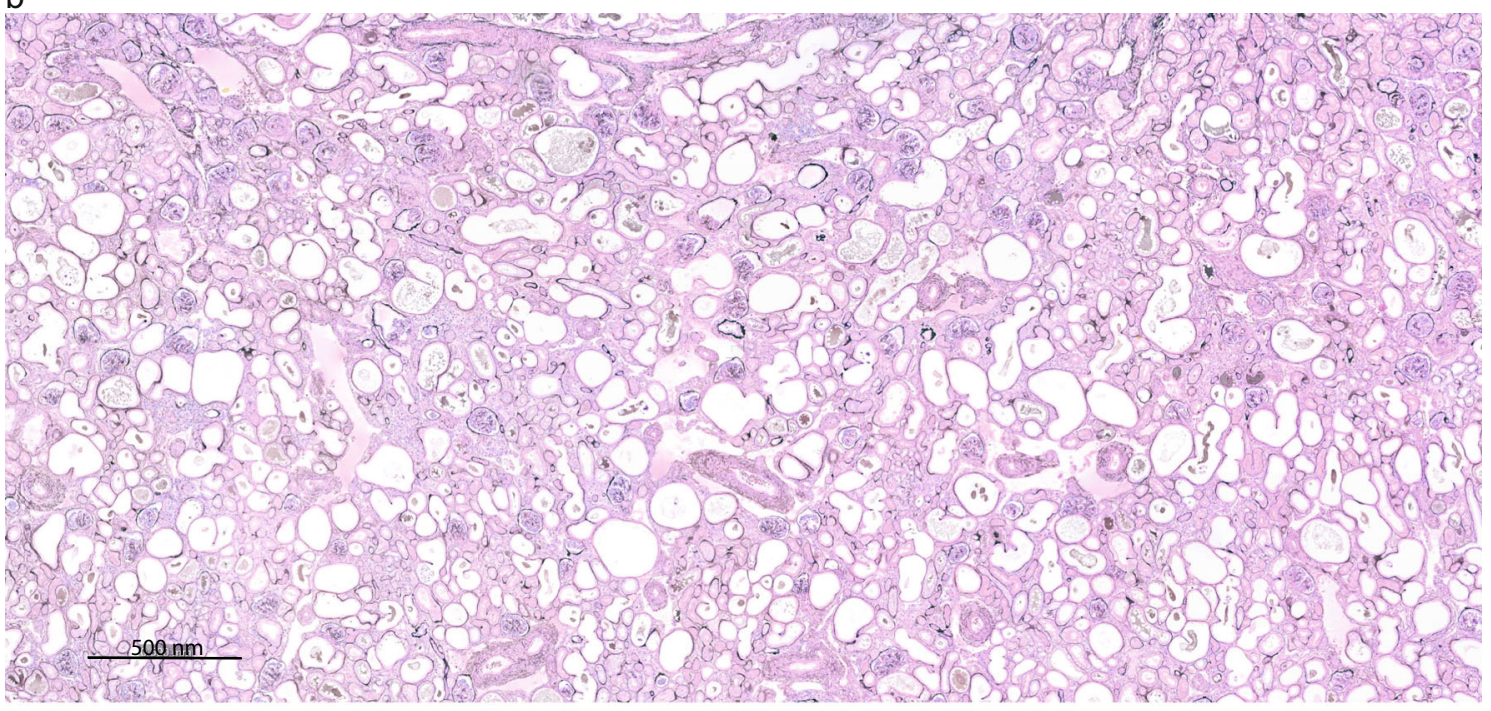

C

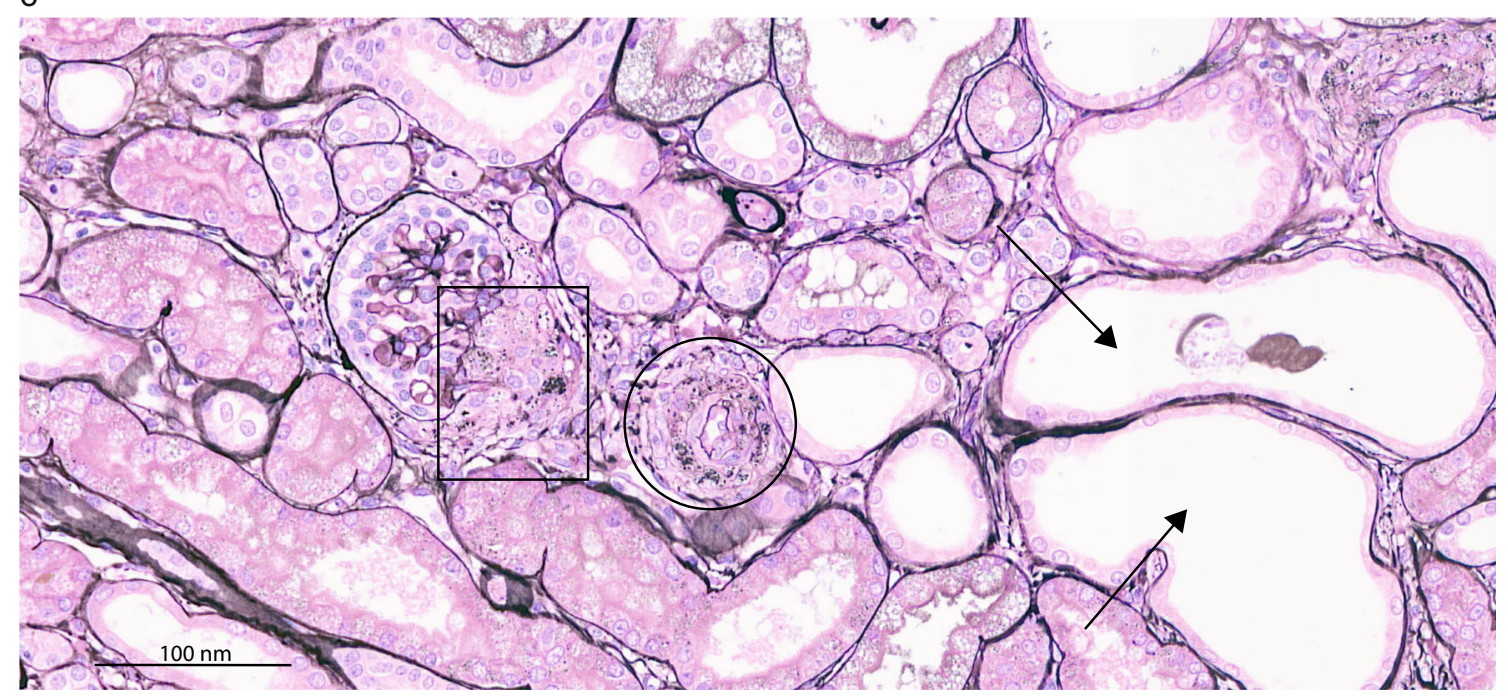

Fig. 1 Pedigree and kidney histology of the proband. a Pedigree of the affected family. I.1 and I.2 are first-degree cousins. b and $\mathbf{c}$ Silver staining, magnification $50 \times$ and $400 \times$. Histology of kidney of proband, obtained at age 3 months. The kidney biopsy shows microcystic changes of tubuli, mostly of distal tubules (arrows). Glomeruli show hypertrophic arterioles (circle) and well-developed juxtaglomerular apparatus (square)

\section{Exome sequencing}

Full description can be found in the Supplementary Methods. In short, genomic DNA was isolated from whole blood, converted into an Illumina library, enriched for exonic regions in which silver-stained granules are visible that may represent renin. Changes are not typical for renal tubular dysgenesis that is rather characterized by atrophic tubules. However, the prominent smooth muscle cells and renin overexpression in the juxtaglomerular apparatus is a common feature in renal tubular dysgenesis

and sequenced on an Illumina HiSeq2000 platform. Sequence reads were aligned to Human Genome Reference Assembly GCRh37/hg19, indexed and subsequently called. Variant annotation and de novo analysis were performed using a custom-designed in-house analysis pipeline. Filtering 
was performed as described in Supplementary Table 1, and pathogenicity of candidate variants was assessed using the Association for Clinical Genomic Science (ACGS) Best Practice Guidelines for Variant Classification 2019. Additionally, we looked for possible pathogenic variants in CYP11B2 (enoding aldosterone synthase) and the RAS genes in the unfiltered data.

\section{Collecting duct function}

To assess whether collecting duct function was present and amenable to treatment with fludrocortisone, we assessed the response to amiloride and fludrocortisone. Amiloride directly blocks the epithelial $\mathrm{Na}^{+}$channel $(\mathrm{ENaC})$, the channel involved in $\mathrm{Na}^{+}$reabsorption in the collecting duct, while fludrocortisone upregulates $\mathrm{ENaC}$ through its action on the mineralocorticoid receptor $[18,19]$. Two days before starting the test, maintenance dose of fludrocortisone $(0.3 \mathrm{mg} /$ day $)$ was stopped. The night before the first test day, the patient received $1 \mathrm{~L} \mathrm{NaCl}$ $0.9 \%(\mathrm{w} / \mathrm{v})$ intravenously. At $8 \mathrm{AM}$, intravenous infusion of $\mathrm{NaCl} 0.9 \% 50 \mathrm{~mL} / \mathrm{h}$ was started, and urine was collected for measurement of sodium, potassium, creatinine and $\mathrm{pH}$. At 10 $\mathrm{AM}(t=0)$, a urine portion was collected, and directly after, amiloride of $20 \mathrm{mg}$ was administered orally. Urine was collected again hourly from $t=120 \mathrm{~min}$ until $t=360 \mathrm{~min}$ for the same measurements. At $t=480 \mathrm{~min}$, intravenous $\mathrm{NaCl} 0.9 \%$ infusion was stopped. The second day of the test was exactly the same, except that fludrocortisone of $1 \mathrm{mg}$ was administered orally instead of amiloride. The only other difference was that the time of drug administration was $3 \mathrm{~h}$ after the start of intravenous $\mathrm{NaCl}$ supplementation instead of $2 \mathrm{~h}$.

\section{Results}

\section{Histology, plasma measurements}

Renal tubular dysgenesis is normally characterized by atrophic tubules, especially seen as an extensive reduction in differentiated proximal tubules. Here, a kidney biopsy at 3 months of age showed the presence of both distal and proximal tubules, although some distal tubules had microcystic changes (Fig. 1b). Arteries were not evidently abnormal in this biopsy; however, arteriolar hypertrophy was observed.

Measurements of the RAS components in the proband and family members can be found in Table 1 . In the proband, angiotensinogen was significantly reduced $(737 \mathrm{nmol} / \mathrm{L})$, but immunoreactive renin and renin activity were elevated (410 $\mathrm{mU} / \mathrm{L}$ and $14.4 \mathrm{nmol}$ Ang I/L·h, respectively), as were levels of angiotensin I (234 ng/L) and angiotensin II $(78.2 \mathrm{ng} / \mathrm{L})$. ACE activity was normal (17.8 U/L). Although reference ranges for healthy individuals are not readily available for all RAS components, RAS levels were not significantly abnormal in family members when compared with the reference data available [20-23]. Aldosterone levels fluctuated between abnormally low and low normal in the patient $(<0.03-$ $0.15 \mathrm{nmol} / \mathrm{L}$ ).

\section{Detection of homozygous AGTR1 p.Arg126* variant}

The low aldosterone levels despite high angiotensin II levels suggests that the patient had a defect of the angiotensin II receptor. Indeed, exome sequencing revealed a homozygous pathogenic variant in AGTR1, c.822C $>$ T (NM_031850.3, dbSNP ID rs397514687), resulting in a premature stop codon (p.Arg164*, full-length AGTR1 has 395 amino acids). The location of the variant is retained in all known splice isoforms [24]. The variant is very rare; it was absent from the Exome Variant Server and has a minor allele frequency of $1.64 \mathrm{e}-5$ in GnomAD, with no homozygote occurrences. Parents were heterozygous. The same variant has been reported in the homozygous state in a Pakistani family with RTD [4]. A founder effect could not be confirmed or excluded. The variant was classified as pathogenic with the ACGS 2019 guidelines.

Of note, no rare variants (minor allele frequency $<0.005$ ) in $C Y P 11 B 2, R E N, A C E$ and $A G T$ were found. An overview of the filtering strategy and a list of variants that remained after filtering can be found in Supplmentary Tables 1, 2 and 3.

\section{Functioning collecting duct}

The recurrent hyperkalemia incited us to study the effect of fludrocortisone on collecting duct function. Within $3 \mathrm{~h}$ of administration, $1 \mathrm{mg}$ fludrocortisone increased urinary $\mathrm{K}^{+}$excretion to $255 \%$ of baseline and decreased $\mathrm{Na}^{+}$excretion by $39 \%$, resulting in a maximum 4.2-fold change decrease in urine $\mathrm{Na}^{+} /$ $\mathrm{K}^{+}$-ratio (Fig. 2). To confirm the functionality of the collecting duct, we also measured the response to amiloride $(20 \mathrm{mg})$. A decrease in urinary $\mathrm{K}^{+}$excretion was observed and resulted in an increase of the urine $\mathrm{Na}^{+} / \mathrm{K}^{+}$-ratio by 1.8 -fold. Furthermore, urinary $\mathrm{pH}$ decreased by 1 and increased by 1.6 after administration of fludrocortistone and amiloride, respectively.

\section{Discussion}

In this report we describe a 28 -year-old male with a homozygous truncating variant in AGTR1 (p.Arg126*) who survived the perinatal period without the need for kidney replacement therapy. The patient reported here had a glomerular filtration rate that was relatively well preserved, especially considering the severity of the mutation and the fact that the variant affected the type-1 angiotensin II receptor, AGTR1 [4, 11]. However, other signs of kidney dysfunction affected the patient throughout life, including several episodes of acute kidney injury at young age, hypotensive episodes, chronic tubular 
Table 1 Components of renin-angotensin-aldosterone system

\begin{tabular}{|c|c|c|c|c|c|c|c|}
\hline & PRA & Renin & Aog & Ang I & Ang II & Aldosterone & $\mathrm{ACE}$ \\
\hline & $\mathrm{nmol}$ Ang $\mathrm{I} / \mathrm{L} \cdot \mathrm{h}$ & $\mathrm{mU} / \mathrm{L}$ & $\mathrm{nmol} / \mathrm{L}$ & $\mathrm{ng} / \mathrm{L}$ & $\mathrm{ng} / \mathrm{L}$ & $\mathrm{nmol} / \mathrm{L}$ & $\mathrm{U} / \mathrm{L}$ \\
\hline Reference & $\begin{array}{l}1.2 \\
(0.5-1.7)[20]\end{array}$ & $\begin{array}{l}23 \\
(3-116)[20]\end{array}$ & $745-2340[21]$ & $\begin{array}{l}44 \\
(12-182)[22]\end{array}$ & $1-20[22,23]$ & $0.04-0.66$ & $<20$ \\
\hline Father & 1.43 & 28 & 1709 & 18.3 & 6.2 & NA & \\
\hline Mother & 1.05 & 9.9 & 1938 & BDL & 0.85 & NA & \\
\hline Sibling 1 & 3.53 & 62.2 & 1529 & 15.5 & 11.7 & NA & \\
\hline Sibling 2 & 0.90 & 18.1 & 1528 & 7.3 & 1.8 & NA & \\
\hline Index & 14.4 & 1900 & 737 & 234 & 78.2 & 0.13 & 17.8 \\
\hline
\end{tabular}

Components of renin-angotensin-aldosterone system in family members. Aldosterone was measured in the seated position after 5 min of rest. At the moment of measurement of renin and aldosterone, the index was taking $\mathrm{NaCl}$ supplements of up to $3 \mathrm{~g} /$ day and fludrocortisone of $0.3 \mathrm{mg} / \mathrm{day}$, and all tested individuals were of adult age

$A C E$, angiotensin-converting enzyme; $A n g$, angiotensin; $A$ og, angiotensinogen; $B D L$, below detection limit; $N A$, not assessed; $P R A$, plasma renin activity

a

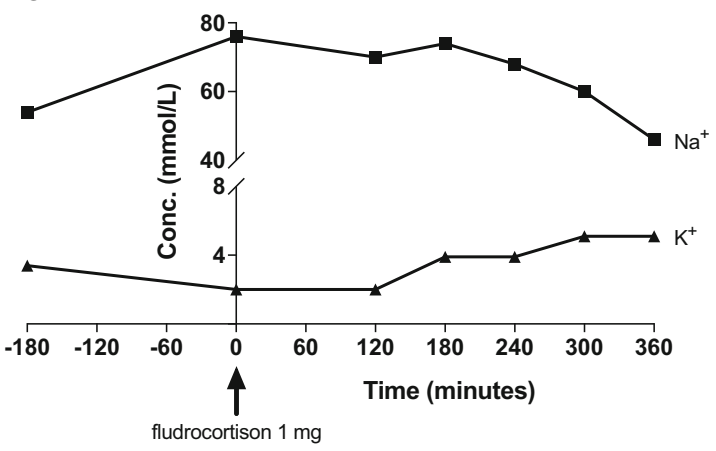

C

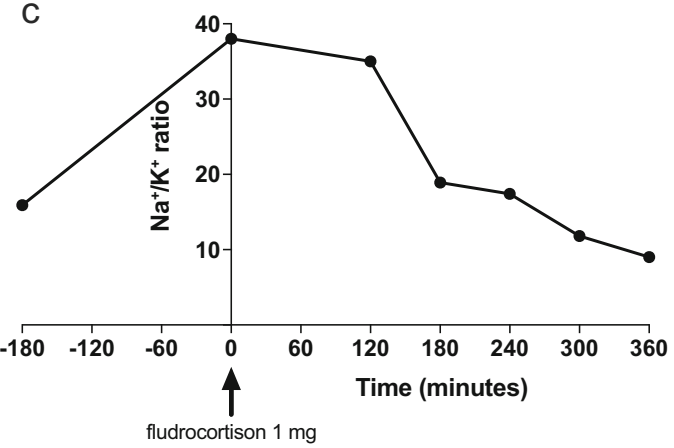

e

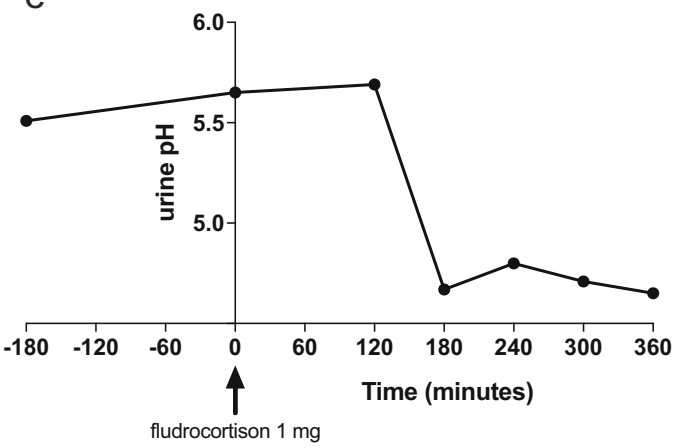

Fig. 2 Collecting duct function in the proband. Urinary excretion of $\mathrm{Na}^{+}$, $\mathrm{K}^{+}$and $\mathrm{H}^{+}$after oral administration of amiloride $20 \mathrm{mg}$ (panels a, $\mathbf{c}$ and $\mathbf{e}$ ) or fludrocortisone $1 \mathrm{mg}$ (panels $\mathbf{b}, \mathbf{d}$, and $\mathbf{f}$ ) in the proband. Intravenous infusion with $0.9 \%(\mathrm{w} / \mathrm{v}) \mathrm{NaCl}(50 \mathrm{~mL} / \mathrm{h})$ was started at the first b
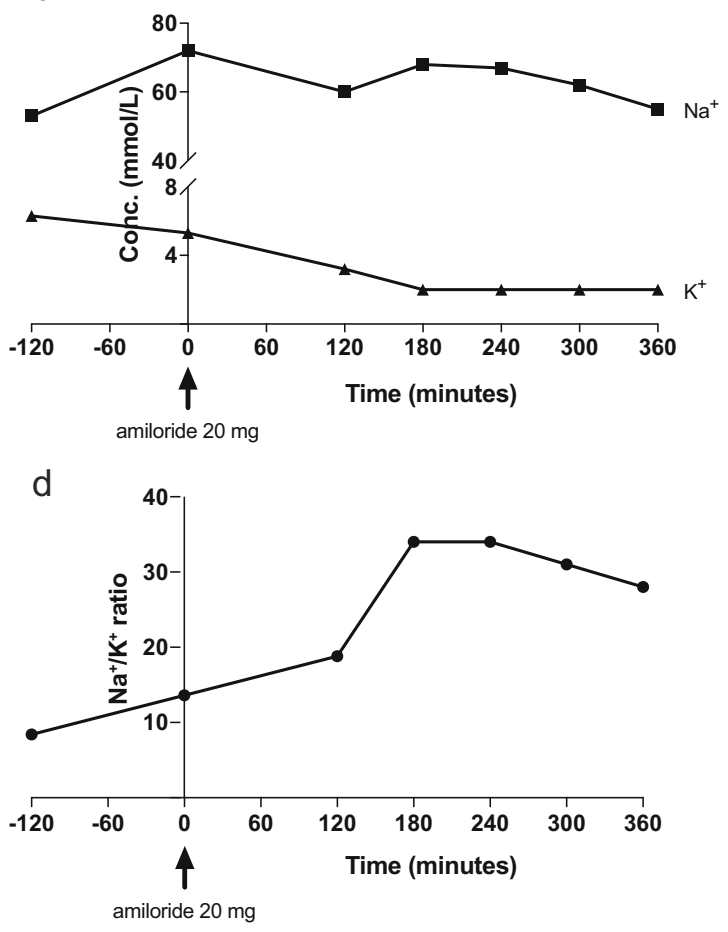

f

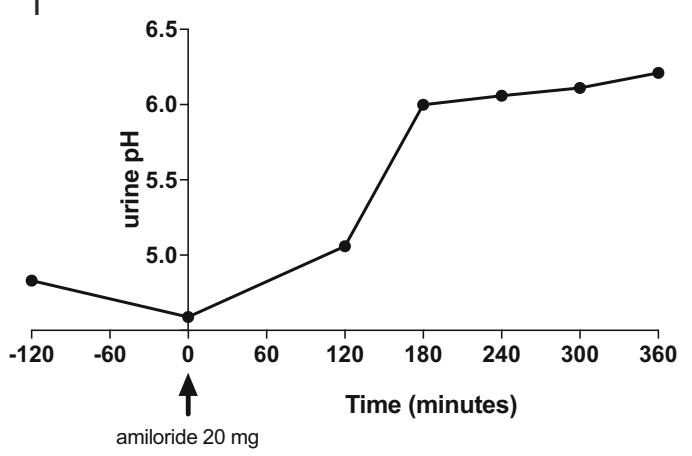

measurement point (i.e., $t=-120 \mathrm{~min}$ for panels a, $\mathbf{c}$, and $\mathbf{e}$ and $t=$ $-180 \mathrm{~min}$ for panels $\mathbf{b}, \mathbf{d}$ and $\mathbf{f}$ ). $\mathbf{a}$ and $\mathbf{b}$ Urinary excretion of $\mathrm{K}^{+}$and $\mathrm{Na}^{+}$. $\mathbf{c}$ and $\mathbf{d ~ N a} / \mathrm{K}^{+}$-ratio. e and $\mathbf{f}$ Urinary $\mathrm{pH}$ 
salt-wasting, impaired urinary concentrating ability with polyuria-polydipsia, recurrent hyperkalemia, a severely reduced GFR and proteinuria. Anemia, although of transient nature, was present as well, resembling three cases with pathogenic variants in $A C E$ [11]. Lastly, we provide new evidence to support the use of fludrocortisone for the treatment of recurrent hyperkalemias in RTD.

With a patient-tailored functional test, we show that fludrocortisone can increase $\mathrm{K}^{+}$excretion and might mitigate $\mathrm{Na}^{+}$wasting in RTD. Fludrocortisone stimulates the aldosterone receptor, resulting in $\mathrm{ENaC}$ upregulation and subsequent excretion of $\mathrm{K}^{+}$and $\mathrm{H}^{+}$ions in healthy individuals. We provide evidence that this mechanism is still operative in patients without AGTRI function and low levels of circulating aldosterone. In support of this mechanism, we show that $\mathrm{H}^{+}$excretion is also stimulated by the administration of fludrocortisone and that amiloride has the exact opposite effect on urinary $\mathrm{K}^{+}$and $\mathrm{H}^{+}$ excretion. The use of fludrocortisone as a treatment in RTD patients has been suggested before $[6,10,25]$. However, the exact effects of fetal RAS dysfunction on the development of the different tubular segments are still largely unknown, as is the functionality of the different segments and molecular transporters. Tests such as those we describe here are therefore of great importance to justify the lifelong use of drugs. Based on our results, fludrocortisone treatment was continued to prevent the recurrence of hyperkalemias that sometimes reached symptomatic, life-threatening levels.

The fact that our patient survived the perinatal period is remarkable. In 2014, when approximately 150 cases of RTD had been reported, data on only ten long-term survivors was available (reviewed in [1]) [1, 4, 7, 14, 26-28]. Since then, only seven more survivors have been described [5, 6, 10-12]. The patient we present here is the only reported long-term survivor with biallelic variants in AGTR1. Furthermore, most survivors had missense variants or single amino acid deletions, leaving the possibility open that some residual function was present. It has been suggested that vasopressin might be a life-saving therapy to treat hypotension in these children $[6,10,12]$. Unfortunately, most children die in utero or shortly after birth and thus do not get the chance to receive such treatment. As an example, two affected siblings in a Pakistani family with the same biallelic p.Arg126* AGTR1 variant died in the first day after birth [4]. The degree of oligohydramnios in our patient was milder than what has been reported for most patients, especially judged by the extent of neonatal respiratory distress that is often observed $[5,6,10$, $12-14,28,29]$. Furthermore, the patient reported here was not anuric or severely oligouric after birth. Lastly, the kidney biopsy did not show full-blown RTD: proximal tubules were mostly normal, in agreement with other available kidney histology reports from survivors [5, 11, 27], and although arterioles showed hypertrophic changes, arteries did not show evident wall thickening, in contrast to reports from both survivors and nonsurvivors $[3-5,11,14,30]$. We hypothesize that the perinatal preservation of glomerular filtration and urine production might have protected our patient from severe complications such as pulmonary hypoplasia and the damaging effects of kidney failure itself, which, together with adequate supportive care, allowed our patient to survive the perinatal period.

Taken together, based on the findings in our patient with a homozygous truncating variant in AGTR1, we encourage clinicians and patients to be aware of the multitude of types of kidney dysfunction that can occur over a lifetime in survivors with RTD. Special care should be taken to avoid eliciting acute kidney injury and associated decline in glomerular filtration, complications of (peri-operative) hypotension and situations that provoke hyperkalemia. On the other hand, this study shows that the prognosis can be good, even in genetically very severe cases. Lastly, this study provides physiological evidence to support the use of fludrocortisone for hyperkalemia and salt-wasting in RTD.

Supplementary Information The online version contains supplementary material available at https://doi.org/10.1007/s00467-021-05018-7.

Acknowledgements We thank Pedro San-Cristobal for his contributions to the genetic investigations.

\section{Declerations}

Ethics approval The study was executed in compliance with the ethical principles formulated by the Declaration of Helsinki. The local ethics committee confirmed that this report (study ID 2020-6776) does not fall under the Dutch medical research involving human subjects act (WMO). Individuals gave informed consent for exome sequencing and for publishing this case report.

Conflict of interest The authors declare that they have no competing interests.

Open Access This article is licensed under a Creative Commons Attribution 4.0 International License, which permits use, sharing, adaptation, distribution and reproduction in any medium or format, as long as you give appropriate credit to the original author(s) and the source, provide a link to the Creative Commons licence, and indicate if changes were made. The images or other third party material in this article are included in the article's Creative Commons licence, unless indicated otherwise in a credit line to the material. If material is not included in the article's Creative Commons licence and your intended use is not permitted by statutory regulation or exceeds the permitted use, you will need to obtain permission directly from the copyright holder. To view a copy of this licence, visit http://creativecommons.org/licenses/by/4.0/.

\section{References}

1. Gubler MC (2014) Renal tubular dysgenesis. Pediatr Nephrol 29: 51-59

2. Yosypiv IV (2020) Renin-angiotensin system in mammalian kidney development. Pediatr Nephrol 36:479-489. https://doi.org/10. 1007/s00467-020-04496-5 
3. Gribouval O, Gonzales M, Neuhaus T, Aziza J, Bieth E, Laurent N, Bouton JM, Feuillet F, Makni S, Amar HB, Laube G, Delezoide AL, Bouvier R, Dijoud F, Ollagnon-Roman E, Roume J, Joubert M, Antignac C, Gubler MC (2005) Mutations in genes in the reninangiotensin system are associated with autosomal recessive renal tubular dysgenesis. Nat Genet 37:964-968

4. Gribouval O, Morinière V, Pawtowski A, Arrondel C, Sallinen SLL, Saloranta C, Clericuzio C, Viot G, Tantau J, Blesson S, Cloarec S, Machet MC, Chitayat D, Thauvin C, Laurent N, Sampson JR, Bernstein JA, Clemenson A, Prieur F, Daniel L, LevyMozziconacci A, Lachlan K, Alessandri JL, Cartault F, Rivière JP, Picard N, Baumann C, Delezoide AL, Belar Ortega M, Chassaing N, Labrune P, Yu S, Firth H, Wellesley D, Bitzan M, Alfares A, Braverman N, Krogh L, Tolmie J, Gaspar H, Doray B, Majore S, Bonneau D, Triau S, Loirat C, David A, Bartholdi D, Peleg A, Brackman D, Stone R, DeBerardinis R, Corvol P, Michaud A, Antignac C, Gubler MC, Ortega MB, Chassaing N, Labrune P, Yu S, Firth H, Wellesley D, Bitzan M, Alfares A, Braverman N, Krogh L, Tolmie J, Gaspar H, Doray B, Majore S, Bonneau D, Triau S, Loirat C, David A, Bartholdi D, Peleg A, Brackman D, Stone R, DeBerardinis R, Corvol P, Michaud A, Antignac C, Gubler MC (2012) Spectrum of mutations in the renin-angiotensin system genes in autosomal recessive renal tubular dysgenesis. Hum Mutat 33:316-326

5. Hibino S, Sasaki H, Abe Y, Hojo A, Uematsu M, Sekine T, Itabashi $\mathrm{K}$ (2015) Renal function in angiotensinogen gene-mutated renal tubular dysgenesis with glomerular cysts. Pediatr Nephrol 30:357-360

6. Richer J, Daoud H, Geier P, Jarinova O, Carson N, Feberova J, Ben Fadel N, Unrau J, Bareke E, Khatchadourian K, Bulman DE, Majewski J, Boycott KM, Dyment DA (2015) Resolution of refractory hypotension and anuria in a premature newborn with loss-offunction of ACE. Am J Med Genet A 167:1654-1658

7. Schreiber R, Gubler MC, Gribouval O, Shalev H, Landau D (2010) Inherited renal tubular dysgenesis may not be universally fatal. Pediatr Nephrol 25:2531-2534

8. Pryde PG, Sedman AB, Nugent CE, Barr M (1993) Angiotensinconverting enzyme inhibitor fetopathy. J Am Soc Nephrol 3:15751582

9. Martinovic J, Benachi A, Laurent N, Daikha-Dahmane F, Gubler MC (2001) Fetal toxic effects and angiotensin-II-receptor antagonists. Lancet 358:241-242

10. Ruf K, Wirbelauer J, Beissert A, Frieauff E (2018) Successful treatment of severe arterial hypotension and anuria in a preterm infant with renal tubular dysgenesis- a case report. Matern Health Neonatol Perinatol 4:27

11. Fila $\mathrm{M}$, Morinière $\mathrm{V}$, Eckart $\mathrm{P}$, Terzic $\mathrm{J}$, Gubler MC, Antignac $\mathrm{C}$, Heidet L (2020) Bi-allelic mutations in renin-angiotensin system genes, associated with renal tubular dysgenesis, can also present as a progressive chronic kidney disease. Pediatr Nephrol 35: 1125-1128. https://doi.org/10.1007/s00467-020-04524-4

12. Kondoh T, Kawai Y, Matsumoto Y, Kumagai N, Miyata M, Tanaka K, Hibino S, Fujita N, Ikezumi Y (2020) Management of a preterm infant with renal tubular dysgenesis: a case report and review of the literature. Tohoku J Exp Med 252:9-14

13. Kim SY, Kang HG, Kim EK, Choi JH, Choi Y, Cheong HI (2012) Survival over 2 years of autosomal-recessive renal tubular dysgenesis. Clin Kidney J 5:56-58

14. Uematsu M, Sakamoto O, Nishio T, Ohura T, Matsuda T, Inagaki T, Abe T, Okamura K, Kondo Y, Tsuchiya S (2006) A case surviving for over a year of renal tubular dysgenesis with compound heterozygous angiotensinogen gene mutations. Am J Med Genet A 140:2355-2360

15. Derkx FH, Tan-Tjiong L, Wenting GJ, Boomsma F, Man in 't Veld AJ, Schalekamp MA (1983) Asynchronous changes in prorenin and renin secretion after captopril in patients with renal artery stenosis. Hypertension 5:244-256

16. Admiraal P, Danser A, Jong MS, Pieterman H, Derkx F, Schalekamp M (1993) Regional angiotensin II production in essential hypertension and renal artery stenosis. Hypertension 21:173-184

17. Danser AJ, van Kesteren CA, Bax WA, Tavenier M, Derkx FH, Saxena PR, Schalekamp MA (1997) Prorenin, renin, angiotensinogen, and angiotensin-converting enzyme in normal and failing human hearts: evidence for renin binding. Circulation 96:220-226

18. Kellenberger S, Schild L (2015) International Union of Basic and Clinical Pharmacology. XCI. Structure, function, and pharmacology of acid-sensing ion channels and the epithelial $\mathrm{Na}+$ channel. Pharmacol Rev 67:1-35

19. Walsh SB, Shirley DG, Wrong OM, Unwin RJ (2007) Urinary acidification assessed by simultaneous furosemide and fludrocortisone treatment: an alternative to ammonium chloride. Kidney Int 71:1310-1316

20. Campbell DJ, Nussberger J, Stowasser M, Danser AH, Morganti A, Frandsen E, Ménard J (2009) Activity assays and immunoassays for plasma renin and prorenin: information provided and precautions necessary for accurate measurement. Clin Chem 55:867-877

21. Derkx FH, Stuenkel C, Schalekamp MP, Visser W, Huisveld IH, Schalekamp MA (1986) Immunoreactive renin, prorenin, and enzymatically active renin in plasma during pregnancy and in women taking oral contraceptives. J Clin Endocrinol Metab 63:1008-1015

22. Admiraal PJ, Derkx FH, Danser AH, Pieterman H, Schalekamp MA (1990) Metabolism and production of angiotensin I in different vascular beds in subjects with hypertension. Hypertension 15:44-55

23. Balcarek J, Sevá Pessôa B, Bryson C, Azizi M, Ménard J, Garrelds IM, McGeehan G, Reeves RA, Griffith SG, Danser AH, Gregg R (2014) Multiple ascending dose study with the new renin inhibitor VTP-27999: nephrocentric consequences of too much renin inhibition. Hypertension 63:942-950

24. Curnow KM, Pascoe L, Davies E, White PC, Corvol P, Clauser E (1995) Alternatively spliced human type 1 angiotensin II receptor mRNAs are translated at different efficiencies and encode two receptor isoforms. Mol Endocrinol 9:1250-1262

25. Min J, Cho MH, Bae SP, Shin SH, Ha IS, Cheong HI, Kang HG (2020) A premature baby with severe oligohydramnios and hypotension: a case report of renal tubular dysgenesis. J Korean Med Sci 35:e283

26. Bacchetta J, Dijoud F, Bouvier R, Putet G, Gubler MC, Cochat P (2007) Renal tubular dysgenesis and mutation in the renin gene. Arch Pediatr 14:1084-1087

27. Zingg-Schenk A, Bacchetta J, Corvol P, Michaud A, Stallmach T, Cochat P, Gribouval O, Gubler MC, Neuhaus TJ (2008) Inherited renal tubular dysgenesis: the first patients surviving the neonatal period. Eur J Pediatr 167:311-316

28. Uematsu M, Sakamoto O, Ohura T, Shimizu N, Satomura K, Tsuchiya S (2009) A further case of renal tubular dysgenesis surviving the neonatal period. Eur J Pediatr 168:207-209

29. Dilliott AA, Wang J, Brown E, Singh G, Shkrum MJ, Clin M, Rupar CA, Hegele RA, Siu VM (2020) A novel homozygous variant in REN in a family presenting with classic features of disorders involving the renin-angiotensin pathway, without renal tubular dysgenesis. Am J Med Genet A 182:2284-2290

30. Gubler MC, Antignac C (2010) Renin-angiotensin system in kidney development: renal tubular dysgenesis. Kidney Int 77:400-406

Publisher's note Springer Nature remains neutral with regard to jurisdictional claims in published maps and institutional affiliations. 